\title{
Comparative Study on Egg Quality traits of Indigenous Chickens and Their F1-Crosses with the Sasso Chicken Breed in Sheka Zone, South Western Ethiopia
}

\author{
Walelegne Alemneh", ${ }^{1, *}$ Aberra Melesse², Kefyalew Berihun ${ }^{2}$ \\ ${ }^{1}$ Department of Animal Science, Mizan Agricultural Technical Vocational Education and Training College, P.O. Box 217, Mizan \\ Teferi, Ethiopia. \\ ${ }^{2}$ School of Animal and Range Sciences, Hawassa University, P.O. Box 5, Hawassa, Ethiopia.
}

How to cite this paper: Walelegne Alemneh, Aberra Melesse, Kefyalew Berihun. (2021) Comparative Study on Egg Quality traits of Indigenous Chickens and Their F1-Crosses with the Sasso Chicken Breed in Sheka Zone, South Western Ethiopia. International Journal of Food Science and Agriculture, 5(3), 430-439.

DOI: 10.26855/ijfsa.2021.09.013

Received: June 30, 2021

Accepted: July 24, 2021

Published: August 13, 2021

*Corresponding author: Walelegne Alemneh, Department of Animal Science, Mizan Agricultural Technical Vocational Education and Training College, P.O. Box 217, Mizan Teferi, Ethiopia.

Email: wala.2008abg@gmail.com

\begin{abstract}
The study was conducted in three districts of Sheka zone in southern Ethiopia with the objective of comparing the egg quality traits of indigenous and F1-crosses (indigenous and Sasso) chickens. Six Kebeles were purposely selected from the three districts. A total of 180 households were purposely selected which possess a minimum of 3 adult chickens used for egg quality evaluation. A total of 600 eggs were used to assess the egg quality parameters from both breeds. The results indicated that the average values of external egg qualities (in $\mathrm{cm}$ ) in local chickens were $43.23 \mathrm{~g}, 3.25,4.27,76.5 \%, 0.36 \mathrm{~mm}$, and 34.7 for egg weight, egg width, egg length, shape index, shell thickens, and egg shall breaking strength $(\mathrm{N})$, respectively. The corresponding average values for same traits of F1-crosses (genotype 2 and 3) were (52.16, $52.56 \mathrm{~g}),(3.69,3.36 \mathrm{~cm}),(4.84,4.7 \mathrm{~cm}),(75.86$, $71.69 \%),(0.32,0.31 \mathrm{~mm})$ and $(34.04,35.19)$, respectively. The F1-crosses (genotype 2 and 3 ) reared in the three districts had higher $(p<0.05)$ external egg quality values than those of local chickens. However, local chickens reared in the three districts produced eggs with the highest shell thickness and shape index than those of the F1-crosses (genotype 2 and 3) except the Masha genotype 2 chickens which had higher values of shape index than local chickens. The mean values (in $\mathrm{cm}$ ) of albumen height, yolk height, yolk width, yolk index, yolk color and Haugh unit in local chickens were 4.59, 14.9, 35, 43.1\%, 9.69 and 71.2, respectively. The corresponding mean values for F1-crosses were 4.69, 14.8, 35.6, $42.4 \%, 9.87$ and $67.6 \%$, respectively. The average values of internal egg quality traits did not differ ( $>0.05$ ) among the local and F1-crossbred chickens except Haugh unit. The current study revealed that the local chickens were superior in shell thickness and had similar internal quality values to that of F1-crosses and thus might be recommended for egg production purposes. Besides, a comparative on-farm performance study in the egg production and hatchability of the eggs and market acceptability of pure Sasso chicken breed and their F1-crosses is needed.
\end{abstract}

\section{Keywords}

Indigenous Chicken, Sasso Chicken breed, F1-Crosses, Sheka Zone, Egg Quality 


\section{Introduction}

Ethiopia, with its wide variations in agro-climatic conditions, possesses one of the largest and the most diverse plant and animal genetic resources in the world [1]. In Ethiopia, the word poultry is synonymous with domestic chicken (Gallus domesticus) because other types of poultry are almost unknown as sources of egg and meat [2]. Indigenous poultry contribute almost $99 \%$ of the national egg and poultry meat production [3]. Indigenous chickens are reared in the country for basic social and economic needs including cash income; hatching for replacement home consumption as well as socio-cultural and religious ceremonies $[4,5]$. All over the developing world, these low-input, low output poultry-husbandry systems are an integral component of the livelihoods of most of rural, peri-urban and some urban households and are likely to continue to meet this role for the foreseeable future [6].

Indigenous chickens are preferred over exotic chickens, because of their pigmentation, taste, flavour and leanness [7]. Variations in ecology and socio-cultural preferences result in different poultry species dominating smallholder production systems in different regions of the world [8]. Along with ethnic affiliation, gender may also affect the individual smallholder's choice of breed as well as the symbolic values attached to different types of poultry [9].

However, the indigenous chicken seems to have low performances comparatively with exotic or hybrid or selected poultry breeds. In this respect, most of the studies carried out in African and Middle Eastern countries on local poultries had shown that they have low size of eggs and chicks $[10,11]$ also low parameters relative to meat and eggs performances, comparatively to usual norms in industrial poultry. This may be attributed, in addition to genetic limits, with the extensive poultry husbandry systems generally practiced by farmers and which are marked by unbalanced feeding, inadequate housing and inappropriate veterinary cares and treatments [10].

Both external and internal qualities of eggs are major importance to the egg industry worldwide. However, they are not being given due attention in the developing world, where the majority of the eggs are coming from free scavenging village chicken, as compared to that of the developed world [12]. However, within the aim of poultry productivity, different breed of exotic chickens (Rhode Island Red, Australorp, New Hampshire and White Leghorns) where imported to Ethiopia since the year 1950's. Higher Learning Institution, Research Institutions, Ministry of Agriculture (Livestock and Fishery Development Minister) and nongovernmental organizations (NGO’s) have disseminated many exotic types of chicken to farmers and urban based small-scale poultry producers [13]. Similarly, Sasso breeds were introduced since 2015 for improvement of chicken productivity in the study zone. A study was conducted by [14] to assess the egg production, body weight and the linear body measurement traits of three exotic breeds including Sasso reared in two agro-ecological zones of Sidama zone. Nevertheless, the egg production traits and hatchability of F1 crosses between local chicken and Sasso breed had F1-crossesnot yet studied. In addition to this, the internal and external egg quality traits of indigenous chickens reared in the current study area were not described. Apart from the stated research gap, the evaluation of the egg quality traits of local chickens and their crosses with Sasso breed under traditional management condition would provide important information for the policy makers to take appropriate decisions on the continuation of using the Sasso breed in improving the livelihood of the rural community of the study area. Based on the above considerations, the current study was initiated to carry out a comparative study on egg quality parameters of indigenous and exotic chickens under scavenging production system.

\section{Materials and Methods}

\subsection{Description of the Study Area}

The study was conducted in Sheka-Zone of the South Nation Nationality People Regional State (SNNPR). Administratively it is divided to three districts, namely, Masha, Yeki and Anderacha (Gecha), which are further divided into 57 peasant associations (SZLFDO, 2017). According to [15], it has a total human population of 199,671 (98,439 female and 101,232 males from these 34,638 urbans and 165,033 rural) and a total surface area of 2,387.5 $\mathrm{km}^{2}$ of land. According to the data from the Livestock and Fishery Development Office (LFDO), the Zone lies between $7^{0} 12^{\prime}-7^{0} 89^{\prime}$ North latitude and $35^{0} 24^{\prime}-37^{0} 90^{\prime}$ East longitude with an elevation ranging 1,001-3,000 meters above sea level (SZLFDO, 2017). The zonal capital city Masha is situated $951 \mathrm{~km}$ from Hawasaa and $650 \mathrm{~km}$ away from Addis Ababa. The zone is bordered in South by Bench Maji Zone, in South west by Gambella Regional State, in North West by Oromia Regional State, and in the Northeast by Kaffa Zone.

The zone has livestock population of Cattle (137,652), Sheep (58,806), Goats (20,212), Horses (9,661), Mules (975), Donkeys (2,576), Camels (127), Poultry $(163,783)$, and Beehives $(88,070)[16]$. The main agricultural practice in the area is, coffee plantations, spices, pulses \& cereal crop production, cattle fattening, apiculture, and animal farming. According to the land utilization data of the region, 64,425.58 ha cultivated land, 4,387 ha grazing land, 115,192 ha of land is covered by forest, bushes and shrub and 30,760 ha of land covered by others.

The agro-ecology of the zone includes $17.61 \%$ kola (lowland), 59.81\% weinadega (Mid-land), and 22.58\% dega (High land) (SZLFDO, 2017). The mean annual temperature of the zone ranges between $15.1-27.55^{\circ} \mathrm{C}$ and the mean 
annual rain falls range from 1,172 to $2,200 \mathrm{~mm}$. The climate of the area is characterized by a long rainy season (June-November) accounting for $75 \%$ of the annual rainfalls with a peak fall in September. The short rainy season extends from March to May with a peak fall in May and the dry season occurs between November and March. Agricultural seasons of the zone are "Mehar" and "Belg". Mehar is a rainy season which ranges from June to October, Belg from March to May.

\subsection{Sampling Design}

A purposive multi-stage and random sampling technique was used in order to determine the number of Kebeles and households to cover all the three districts. At $1^{\text {st }}$ stage, after consulting the district Agricultural experts, extension agents, and key informants, about F1-crosses and 2 Kebeles from each district (in total 6 Kebeles) were selected purposively based on the availability of chickens (F1-crosses of Sasso with local) and the accessibility of the Kebeles. In the $2^{\text {nd }}$ stage of sampling, 30 households (15 for local and 15 for F1-crosses) were selected purposively from each Keble, that possess a minimum of 5 adult (one year and above) F1-crossesand local chickens. The total numbers of households considered therefore were 180 (90 households that possess local chicken and 90 households that possess F1-crosses chickens). All 180 households were used for the collection of egg for the determination of egg quality traits.

All crossbred chickens included in this study are the first generations of crosses (F1-crosses) that were obtained from the Sasso chicken breeds that had been distributed in 2015 in the study area and this was checked and verified by asking individual households during the survey period.

\subsection{Data Collection Procedures}

For the determination of egg quality parameters, a total of 600 eggs were used which representing 300 eggs for local and 300 eggs for F1-crosses. Four hundred eggs that were collected in the first round were transported to the laboratory of Jimma University, College of Agriculture and Veterinary Medicine where all egg quality parameters were determined. In the second round, 200 eggs were collected and transported to School of Animal and Range Sciences of Hawassa University for the subsequent quality assessment. Eggs were transported by using appropriate portable refrigerator in order to avoid quality deterioration and breakage during collection and transportation. The whole eggs were collected and evaluate in the two consecutive days to avoid quality deterioration.

For external egg quality traits, egg width and egg length were measured using digital calliper. The breaking strength of the egg was measured by egg force strength material. After measuring the external quality traits, each egg was opened on flat glass plate to measure the following traits: shell thickness, yolk colour, yolk height, and albumen height and yolk diameter. Yolk color was measured using roach color fun that contains a series of fifteen colored plastic strips. Egg Shell thickens (mm) was measured using "digital calliper" by removing the inner shell membranes after dried 24 hours and it was measured at three places, first at the broad end, second at narrow end and third at the middle parts of the egg shell and then averaged. Yolk height and albumen height was measured by tripod micrometre at the highest point of egg yolk and albumen respectively. The Yolk diameter (width) was measured by a ruler (at Jimma laboratory) and digital calliper (at Hawassa laboratory) after breaking the egg on flat tray and separated from albumen.

Egg shape index was computed by dividing the egg width by its length. Yolk index was computed by dividing the yolk height by its diameter. Haugh unit was calculated using the following formula adopted from [17].

$\mathrm{HU}=100 \log \left(\mathrm{H}+7.57-1.7 \mathrm{~W}^{0.37}\right)$

Where, $\mathrm{HU}=$ Haugh unit, $\mathrm{H}=$ observed height of the albumen (mm), $\mathrm{W}=$ Egg weight (g).

Breaking strength was for all eggs collected from Yeki and Anderacha was computed at the laboratory of Jimma University. However, the breaking strength of those eggs collected from the Masha district was not determined due to the absence of the equipment in the laboratory of Hawassa University.

\subsection{Statistical Analysis}

All the data were analysed using the GLM procedure of Statistical analysis of software (SAS, 2012, ver. 9.4). Mean comparisons were conducted using Tukey's Standardized Range (HSD) test. The values were considered significant at $\mathrm{P}<0.05$ unless noted otherwise.

The following statistical models were used for the analysis of the data:

Model I: For egg quality parameters

$\mathrm{Y}_{\mathrm{ijk}}=\mu+\mathrm{B}_{\mathrm{i}}+\mathrm{D}_{\mathrm{j}}+\mathrm{Bi}^{*} \mathrm{D}_{\mathrm{j}}+\mathrm{Eijk}$

Where:

$\mathrm{Y}_{\mathrm{ijk}}=$ the value of the dependent observed variables

$\mu=$ overall mean

$\mathrm{B}_{\mathrm{i}}=$ the effect of $\mathrm{i}^{\text {th }}$ chicken breed $(\mathrm{i}=$ local, $\mathrm{F} 1$-crosses $)$

$D_{j}=$ the effect of $j^{\text {th }}$ district $(j=1,2 \& 3)$

$B_{i} * D_{j}=$ the interaction effect

Eijk $=$ random error term 


\section{Results}

\subsection{Egg Quality Parameters}

\subsubsection{External Egg Quality Traits}

As indicated in Table 1, the findings of egg weight show that the eggs of genotype 3 hens were heaviest among those reared at Yeki, while the eggs from the local hens were lightest. At Anderacha, there was no difference in egg weight between genotype 2 and 3 while at Masha the reverse was true amongst genotypes 2 and 3 where eggs from genotype 2 were heavier than those of genotype 3. The result related to egg width show that at Yeki and Masha, it was eggs from genotype 2 were widest, while the eggs from local hens had least width at Yeki, but at Masha, it was the eggs from genotype 3 which had the least egg width. The egg length value showed that it was eggs from hens of genotype 3 which were highest among genotype 2 at Yeki, while at Anderacha, it was highest from the local hens. The egg shape index at Masha was similar to those of Yeki. Shell thickens was highest amongst the local hens irrespective of all the studied location. The breaking strength showed variations with higher breaking strength among local hens and genotype 2 reared at Yeki, while it was higher amongst eggs collected from genotype 3 reared at Anderacha.

The data as shown in Table 2, the results related to external egg quality traits among genotypes across locations are presented. The finding shows that egg weight was highest among the local chickens reared at Anderacha, while local chickens reared at Yeki had the least egg weight. With regard to genotype 2, egg weight of least among those reared at Yeki with no differences in the other two locations. In genotype 3, the egg width was highest at Anderacha when compared to other two locations. The egg width value of the local hens was higher at Yeki and Anderacha while for that genotype 2 were highest at Masha. The egg width of genotype 3 was higher at Yeki. The egg length value for the local chicken was higher among those reared at Masha while for hens from genotype 2; followed the similar trends as that of the local hens. The egg length of genotype 3 was higher among those produced at Yeki.

The egg shape index of the local hens was higher at Yeki and Anderacha, while that of genotype 2 was highest at Yeki. Genotype 3 followed the same trait as that of eggs from genotype 2. Shell thickens of eggs from native chicken was higher at Yeki while for genotype 2 the value was higher among those the reared at Anderacha and Masha. As regarded genotype 3, no significance difference was observed across the locations. The breaking strength values were similar across all the locations irrespective of the genotypes.

Table 1. The average $( \pm \mathrm{SD})$ values of external egg quality traits of local and $F 1$ cross with Sasso chickens $(\mathrm{N}=600)$

\begin{tabular}{cccccccccc}
\hline \multirow{2}{*}{ Egg quality } & \multicolumn{3}{c}{$\begin{array}{c}\text { Yaki } \\
\text { Genotype2 }\end{array}$} & Genotype 3 & Local & $\begin{array}{c}\text { Anderacha } \\
\text { Genotype 2 }\end{array}$ & Genotype 3 & Local & $\begin{array}{c}\text { Masha } \\
\text { Genotype 2 }\end{array}$ \\
& Local & Genotype 3 \\
\hline Egg weight & $39.39 \pm 4.1^{\mathrm{a}}$ & $49.6 \pm 4.25^{\mathrm{b}}$ & $51.8 \pm 3.68^{\mathrm{c}}$ & $46.5 \pm 3.7 \mathrm{a}$ & $53.3 \pm 4.64^{\mathrm{b}}$ & $54 \pm 4.59^{\mathrm{b}}$ & $43.8 \pm 3.1^{\mathrm{a}}$ & $53.6 \pm 3.35^{\mathrm{c}}$ & $51.5 \pm 3.81^{\mathrm{b}}$ \\
Egg width & $3.32 \pm 0.35^{\mathrm{a}}$ & $3.81 \pm 0.3^{\mathrm{c}}$ & $3.64 \pm 0.3^{\mathrm{b}}$ & $3.27 \pm 0.4^{\mathrm{a}}$ & $3.17 \pm 0.26^{\mathrm{a}}$ & $3.52 \pm 0.19^{\mathrm{b}}$ & $3.16 \pm 0.3^{\mathrm{b}}$ & $4.09 \pm 0.20^{\mathrm{c}}$ & $2.94 \pm 0.28^{\mathrm{a}}$ \\
Egg length & $4.13 \pm 0.45^{\mathrm{a}}$ & $4.49 \pm 0.4^{\mathrm{b}}$ & $4.9 \pm 0.29^{\mathrm{c}}$ & $4.19 \pm 0.5^{\mathrm{a}}$ & $4.62 \pm 0.37^{\mathrm{b}}$ & $5.08 \pm 0.38^{\mathrm{c}}$ & $4.5 \pm 0 . .47^{\mathrm{b}}$ & $5.42 \pm 0.23^{\mathrm{c}}$ & $4.13 \pm 0.32^{\mathrm{a}}$ \\
Egg shape index & $80.6 \pm 7.3^{\mathrm{b}}$ & $85.2 \pm 6.5^{\mathrm{c}}$ & $74.6 \pm 5.58^{\mathrm{a}}$ & $78.7 \pm 9.9^{\mathrm{b}}$ & $68.8 \pm 3.6^{\mathrm{a}}$ & $69.6 \pm 4.9^{\mathrm{a}}$ & $70.3 \pm 4.9^{\mathrm{a}}$ & $75.6 \pm 2.7^{\mathrm{b}}$ & $70.9 \pm 4.27^{\mathrm{a}}$ \\
Shell thickness & $0.37 \pm .02^{\mathrm{b}}$ & $0.31 \pm 0.01^{\mathrm{a}}$ & $0.31 \pm 0.03^{\mathrm{a}}$ & $0.36 \pm .03^{\mathrm{b}}$ & $0.33 \pm 0.03^{\mathrm{a}}$ & $0.32 \pm 0.03^{\mathrm{a}}$ & $0.36 \pm .02^{\mathrm{c}}$ & $0.32 \pm .02^{\mathrm{b}}$ & $0.31 \pm 0.03^{\mathrm{a}}$ \\
Breaking strength & $35.6 \pm 6.5 \mathrm{~b}$ & $35.20 \pm 7.5$ & $33.95 \pm 7.5$ & $33.7 \pm 5.7^{\mathrm{a}}$ & $32.9 \pm 6.3^{\mathrm{a}}$ & $36.4 \pm 7.3^{\mathrm{b}}$ & $\mathrm{ND}$ & $\mathrm{ND}$ & $\mathrm{ND}$ \\
\hline
\end{tabular}

a,b,c, Means between breeds within districts with different superscript letter are significantly different $(\mathrm{p}<0.05)$; ND = not determined, Genotype $(2)=$ Sasso Rooster X Local Hens, Genotype (3) = Local Rooster X Sasso Hens, breaking strength (N= Newton).

Table 2. The average $( \pm \mathrm{SD})$ values of external egg quality traits of local and F1 cross chickens with Sasso (N=600)

\begin{tabular}{ccccccccccc}
\hline \multirow{2}{*}{ Egg quality traits } & \multicolumn{3}{c}{ Yaki } & & \multicolumn{3}{c}{ Anderacha } & & \multicolumn{2}{c}{ Masha } \\
& Local & Genotype 2 & Genotype 3 & Local & Genotype 2 & Genotype 3 & Local & Genotype 2 & Genotype 3 \\
\hline Egg weight & $39.39 \pm 4.1^{\mathrm{a}}$ & $49.6 \pm 4.25^{\mathrm{a}}$ & $51.8 \pm 3.68^{\mathrm{a}}$ & $46.5 \pm 3.76^{\mathrm{c}}$ & $53.3 \pm 4.64^{\mathrm{b}}$ & $54 \pm 4.59^{\mathrm{b}}$ & $43.8 \pm 3.1^{\mathrm{b}}$ & $53.6 \pm 3.35^{\mathrm{b}}$ & $51.5 \pm 3.81^{\mathrm{a}}$ \\
Egg width & $3.32 \pm 0.35^{\mathrm{b}}$ & $3.81 \pm 0.32^{\mathrm{b}}$ & $3.64 \pm 0.3^{\mathrm{c}}$ & $3.27 \pm 0.35^{\mathrm{b}}$ & $3.17 \pm 0.26^{\mathrm{a}}$ & $3.52 \pm 0.19^{\mathrm{b}}$ & $3.16 \pm 0.3^{\mathrm{a}}$ & $4.09 \pm 0.20^{\mathrm{c}}$ & $2.94 \pm 0.28^{\mathrm{a}}$ \\
Egg length & $4.13 \pm 0.45^{\mathrm{a}}$ & $4.49 \pm 0.39^{\mathrm{a}}$ & $4.9 \pm 0.29^{\mathrm{b}}$ & $4.19 \pm 0.49^{\mathrm{a}}$ & $4.62 \pm 0.37^{\mathrm{a}}$ & $5.08 \pm 0.38^{\mathrm{c}}$ & $4.5 \pm 0.47^{\mathrm{b}}$ & $5.42 \pm 0.23^{\mathrm{b}}$ & $4.13 \pm 0.32^{\mathrm{a}}$ \\
Egg shape index & $80.6 \pm 7.25^{\mathrm{b}}$ & $85.2 \pm 6.52^{\mathrm{c}}$ & $74.6 \pm 5.58^{\mathrm{b}}$ & $78.7 \pm 9.91^{\mathrm{b}}$ & $68.8 \pm 3.64^{\mathrm{a}}$ & $69.58 \pm 4.9^{\mathrm{a}}$ & $70.3 \pm 4.89^{\mathrm{a}}$ & $75.6 \pm 2.72^{\mathrm{b}}$ & $70.9 \pm 4.27^{\mathrm{a}}$ \\
Shell thickness & $0.37 \pm .02^{\mathrm{b}}$ & $0.31 \pm 0.02^{\mathrm{a}}$ & $0.31 \pm 0.03$ & $0.36 \pm .03^{\mathrm{a}}$ & $0.33 \pm 0.03^{\mathrm{b}}$ & $0.32 \pm 0.03$ & $0.36 \pm .02^{\mathrm{a}}$ & $0.32 \pm .02^{\mathrm{ab}}$ & $0.31 \pm 0.03$ \\
Breaking strength & $35.69 \pm 6.45$ & $35.20 \pm 7.54$ & $33.9 \pm 7.46$ & $33.67 \pm 5.71$ & $32.88 \pm 6.3$ & $36.44 \pm 7.3$ & $\mathrm{ND}$ & $\mathrm{ND}$ & $\mathrm{ND}$ \\
\hline
\end{tabular}

a,b,c, Means between breeds across districts with different superscript letter are significantly different $(\mathrm{p}<0.05)$; ND = not determined, Genotype $(2)=$ Sasso Rooster X Local Hens, Genotype (3) = Local Rooster X Sasso Hens, breaking strength (N= Newton). 


\subsubsection{Internal Egg Quality Trait}

As indicated in Table 3, the study shows that hens of genotype 2 reared at Yeki had the highest albumen height, while at Anderacha, eggs from local and genotype 2 hens had higher albumen height, at Masha, however, the albumen height was higher for eggs from genotype 3. Regarding yolk height, no difference across genotype were recorded at Yeki, while the eggs from local and genotype 2 had the highest yolk height at Anderacha, while at Masha, it was the eggs from genotype 3 which had the higher values. The yolk width values were similar across genotypes at Yeki while it was higher for eggs from genotype 3 at Anderacha and genotype 2 for Masha. Yolk index values were higher among the eggs collected from genotype 2 at Yeki while in Anderacha, it was higher for genotype 3 and at Masha, it was higher for the eggs collected from genotype 3 hens. The yolk colour indicated that it was darker in eggs collected from genotype 2 and 3 reared at Yeki while no differences across genotypes was observed in the other two locations. The Haugh unit values showed it was higher among chickens of genotype 2 reared at Yeki and local chickens reared at Anderacha. At Masha however, the eggs from local hens and genotype 3 had higher values when compared to those from genotype 2.

The data as shown in Table 4, the albumen height of eggs from local hens were higher at Masha while similar values were observed eggs from genotypes 2 and 3 . With regard to yolk height, the trends were similar to albumen height as recorded above. The yolk width values from eggs of local chicken were highest at Yeki while that from genotype 2 was higher at Masha. The yolk width values of genotype 3 were higher in Yeki and Anderacha. The values of yolk index were higher among the egg collected from local chicken reared at Masha while for genotype 2 values was higher from eggs collected at Anderacha and Masha. The values for genotype 3 were similar to eggs collected from local hens. The yolk colour values for local hens were darker from those collected at Anderacha and Masha while for the genotype 2 the eggs were darker at Anderacha. The yolk colour eggs from genotype 3 indicated that there were darker at Anderacha and Masha. The Haugh unit values of eggs from the local hens were higher at Masha. Similar trends were observed in the other two genotypes too.

Table 3. The average $( \pm \mathrm{SD})$ values of internal egg quality traits of local chickens and their $F 1$-crosses with Sasso $(\mathrm{N}=600)$

\begin{tabular}{cccccccccc}
\hline \multirow{2}{*}{ Egg quality traits } & \multicolumn{3}{c}{ Yaki } & & \multicolumn{3}{c}{ Anderacha } & & \multicolumn{2}{c}{ Masha } \\
& Local & Genotype2 & Genotype 3 & Local & Genotype 2 & Genotype 3 & Local & Genotype 2 & Genotype 3 \\
\hline Albumen height & $3.16 \pm 0.63^{\mathrm{a}}$ & $4.08 \pm 0.9^{\mathrm{c}}$ & $3.58 \pm 0.53^{\mathrm{b}}$ & $4.75 \pm 1.0^{\mathrm{b}}$ & $4.68 \pm 0.73^{\mathrm{b}}$ & $3.46 \pm 0.39^{\mathrm{a}}$ & $5.84 \pm 0.84^{\mathrm{a}}$ & $6.0 \pm 0.88^{\mathrm{a}}$ & $6.32 \pm 0.81^{\mathrm{b}}$ \\
Yolk height & $12.82 \pm 1.46^{\mathrm{a}}$ & $13.17 \pm 1.45^{\mathrm{a}}$ & $12.66 \pm 1.35^{\mathrm{a}}$ & $14.99 \pm 1.1^{\mathrm{b}}$ & $14.69 \pm 1.13^{\mathrm{b}}$ & $13.7 \pm 0.86^{\mathrm{a}}$ & $16.82 \pm 1.09^{\mathrm{a}}$ & $16.90 \pm 0.88^{\mathrm{a}}$ & $17.82 \pm 0.82^{\mathrm{b}}$ \\
Yolk width & $36.82 \pm 3.15^{\mathrm{a}}$ & $36.18 \pm 3.39^{\mathrm{a}}$ & $36.54 \pm 3.99^{\mathrm{a}}$ & $35.45 \pm 3.3^{\mathrm{ab}}$ & $34.54 \pm 3.90^{\mathrm{a}}$ & $36.66 \pm 4.57^{\mathrm{b}}$ & $32.75 \pm 2.85^{\mathrm{b}}$ & $38.92 \pm 2.60^{\mathrm{c}}$ & $30.68 \pm 2.10^{\mathrm{a}}$ \\
Yolk index & $34.99 \pm 4.42^{\mathrm{a}}$ & $36.59 \pm 4.26^{\mathrm{c}}$ & $34.80 \pm 3.25^{\mathrm{a}}$ & $42.53 \pm 3.9^{\mathrm{b}}$ & $42.99 \pm 5.36^{\mathrm{b}}$ & $37.9 \pm 5.042^{\mathrm{a}}$ & $51.73 \pm 4.36^{\mathrm{b}}$ & $43.62 \pm 2.78^{\mathrm{a}}$ & $58.28 \pm 3.43^{\mathrm{c}}$ \\
Yolk colour & $8.44 \pm 1.39^{\mathrm{a}}$ & $9.12 \pm 1.80^{\mathrm{b}}$ & $9.44 \pm 1.96^{\mathrm{b}}$ & $10.22 \pm 2.15^{\mathrm{a}}$ & $10.28 \pm 1.55^{\mathrm{a}}$ & $10.52 \pm 2.03^{\mathrm{a}}$ & $10.35 \pm 2.03^{\mathrm{a}}$ & $9.64 \pm 2.50^{\mathrm{a}}$ & $10.24 \pm 1.86^{\mathrm{a}}$ \\
Haugh unit & $61.11 \pm 6.25^{\mathrm{b}}$ & $64.13 \pm 8.13^{\mathrm{c}}$ & $57.98 \pm 5.96^{\mathrm{a}}$ & $71.54 \pm 8.32^{\mathrm{c}}$ & $68.31 \pm 5.46^{\mathrm{b}}$ & $55.27 \pm 5.50^{\mathrm{a}}$ & $81.13 \pm 5.68^{\mathrm{b}}$ & $78.44 \pm 6.55^{\mathrm{a}}$ & $81.55 \pm 5.29^{\mathrm{b}}$ \\
\hline
\end{tabular}

$\overline{a, b, c,}$ Means between breeds within districts with different superscript letter are significantly different( $<0.05)$; ND = not determined, Genotype $(2)=$ Sasso Rooster X Local Hens, Genotype (3) = Local Rooster X Sasso Hens.

Table 4. The average $( \pm \mathrm{SD})$ values of internal egg quality traits of local chickens and their $\mathrm{F} 1$-crosses with $\mathrm{Sasso}(\mathrm{N}=600)$

\begin{tabular}{cccccccccc}
\hline \multirow{2}{*}{ Egg quality traits } & \multicolumn{3}{c}{ Yaki } & \multicolumn{3}{c}{ Anderacha } \\
& Local & Genotype 2 & Genotype 3 & Local & Genotype 2 & Genotype 3 & Local & Masha \\
Genotype 2 & Genotype 3 \\
\hline Albumen height & $3.16 \pm 0.63^{\mathrm{a}}$ & $4.08 \pm 0.9^{\mathrm{a}}$ & $3.58 \pm 0.53^{\mathrm{a}}$ & $4.75 \pm 1.0^{\mathrm{b}}$ & $4.68 \pm 0.73^{\mathrm{b}}$ & $3.46 \pm 0.39^{\mathrm{a}}$ & $5.84 \pm 0.84^{\mathrm{c}}$ & $6.0 \pm 0.88^{\mathrm{c}}$ & $6.32 \pm 0.81^{\mathrm{b}}$ \\
Yolk height & $12.82 \pm 1.46^{\mathrm{a}}$ & $13.17 \pm 1.45^{\mathrm{a}}$ & $12.66 \pm 1.35^{\mathrm{a}}$ & $14.99 \pm 1.11^{\mathrm{b}}$ & $14.69 \pm 1.13^{\mathrm{b}}$ & $13.7 \pm 0.86^{\mathrm{b}}$ & $16.82 \pm 1.09^{\mathrm{c}}$ & $16.90 \pm 0.88^{\mathrm{c}}$ & $17.82 \pm 0.82^{\mathrm{c}}$ \\
Yolk width & $36.82 \pm 3.15^{\mathrm{c}}$ & $36.18 \pm 3.39^{\mathrm{b}}$ & $36.54 \pm 3.99^{\mathrm{b}}$ & $35.45 \pm 3.31^{\mathrm{b}}$ & $34.54 \pm 3.90^{\mathrm{a}}$ & $36.66 \pm 4.57^{\mathrm{b}}$ & $32.75 \pm 2.85^{\mathrm{a}}$ & $38.92 \pm 2.60^{\mathrm{c}}$ & $30.68 \pm 2.10^{\mathrm{a}}$ \\
Yolk index & $34.99 \pm 4.41^{\mathrm{a}}$ & $36.59 \pm 4.26^{\mathrm{a}}$ & $34.80 \pm 3.25^{\mathrm{a}}$ & $42.53 \pm 3.92^{\mathrm{b}}$ & $42.99 \pm 5.36^{\mathrm{b}}$ & $37.9 \pm 5.042^{\mathrm{b}}$ & $51.73 \pm 4.36^{\mathrm{c}}$ & $43.62 \pm 2.78^{\mathrm{b}}$ & $58.28 \pm 3.43^{\mathrm{c}}$ \\
Yolk colour & $8.44 \pm 1.39^{\mathrm{a}}$ & $9.12 \pm 1.80^{\mathrm{a}}$ & $9.44 \pm 1.96^{\mathrm{a}}$ & $10.22 \pm 2.15^{\mathrm{b}}$ & $10.28 \pm 1.55^{\mathrm{b}}$ & $10.52 \pm 2.03^{\mathrm{b}}$ & $10.35 \pm 2.03^{\mathrm{b}}$ & $9.64 \pm 2.50^{\mathrm{ab}}$ & $10.24 \pm 1.86^{\mathrm{b}}$ \\
Haugh unit & $61.11 \pm 6.25^{\mathrm{a}}$ & $64.13 \pm 8.13^{\mathrm{a}}$ & $57.98 \pm 5.96^{\mathrm{b}}$ & $71.54 \pm 8.32^{\mathrm{b}}$ & $68.31 \pm 5.46^{\mathrm{b}}$ & $55.27 \pm 5.50^{\mathrm{a}}$ & $81.13 \pm 5.68^{\mathrm{c}}$ & $78.44 \pm 6.55^{\mathrm{c}}$ & $81.55 \pm 5.29^{\mathrm{c}}$ \\
\hline
\end{tabular}

a,b,c, Means between breeds across districts with different superscript letter are significantly different ( $<0.05)$; ND = not determined, Genotype (2) = Sasso Rooster X Local Hens, Genotype (3) = Local Rooster X Sasso Hens. 


\section{Discussion}

\subsection{External Egg Qualities}

The average egg weights of F1-crosses (2 and 3) chicken ( $52.3 \mathrm{gm}$ ) were higher than the local chickens (43.3 gm). The average egg weight of the current finding for F1-crosses is consistent with that of $[17,19]$ reported for crossbreds between local chickens with exotic chicken breeds. The average egg weight of the local chickens in the current study is in line with the finding of $[1,20]$, who reported similar egg weight values for local chickens reared in different parts of the country. However, the egg weight of local chickens observed in the current study is higher than the findings of [19], who reported an average egg weight of 41.1g for the local chickens raised in Chelliya district of Western Showa Zone.

The average egg width and length for local chickens was lower than those of F1-crosses (2 and 3), which might be attributed to the heterosis effect of crossbreds as a result of the inclusion of the genetic potential of the Sasso chicken breed. The average egg width and length of local chickens of the current study is lower than the finding of [21-24]. The average shape index of Yeki chicken was higher than Anderacha and Masha chickens. Because Yeki chicken had higher values of egg width and lower values of egg length. On the other hand, the shape index of Masha chicken had higher value due to its egg length. Thus, egg width might be the determinant factors for higher or lower values of egg shape index and also it indicated that shape index is directly proportional with egg width and inversely proportional with egg length.

The current study of the average egg shape index of local chicken (76.5) is higher than F1-crosses chickens (74.1), which is due to genetic factors. Thus, during the data collection, it has been observed that the local chicken's egg had proportional egg width with that of egg length while the majority of eggs collected from the F1-crosseshad (genotype 2 and 3) round shape indicating the egg width were not proportional to its egg length. This situation has created a problem to distinguish which one is the broad end and narrow end of the egg. The average shape index of the current study is in line with the finding of [19] for the local chicken and its first-generation reciprocal crossbreds with an exotic strain in Cameroon. The current finding of the average shape index of local chicken egg is higher than that of [19, 20], which might be attributed to the age and ecotype as well as to the quality, quantity and nutrient composition of scavenging feed resources available in different localities. The shape index of current study for F1-crosses (genotype 2 and 3 ) is higher than the finding of [24], who reported $72 \%$ value of index for crossbred chickens between the local and Fayoumi in Bangladesh.

The egg shell breaking strength and shell thickness are very important traits to prevent egg breakage during packing and transportation of eggs. The average shell thickens and breaking strength values were generally higher in local chickens than those of F1-crosses (genotype 2 and 3), which is in good agreement with the reports of [24], who reported that the local naked neck chickens had higher shell thickness values than those of F1-crosses (genotype 2 and 3) between local naked-neck chicken and the New Hampshire chicken breeds. Moreover, the current study indicated that the average egg shell thickness of local chicken is higher than the finding of $[21,25,18]$. On the other hand, the average egg shell thickens of F1-crosses (genotype 2 and 3) is higher than the findings of [18, 25], which might be attributed to the quality, quantity and nutrient composition of scavenging feed resources available in different localities. The current finding of shell breaking strength of local chicken (34.7N) is similar with F1-crosses (genotype 2 and 3) chicken (34.6N).Thus, it may be the chickens reared under the same management or production system.

\subsection{Internal Egg Qualities}

The current result showed that average albumen height of local, genotype 2 and genotype 3 chickens reared in Yeki, Anderacha and Masha districts were 3.16, 4.08, $3.58 \mathrm{~mm}, 4.75,4.68,3.46 \mathrm{~mm}$ and 5.84, 6.0, $6.32 \mathrm{~mm}$ respectively. However, the local and genotype 2 chickens reared in Yeki district had lower albumen height than those reared in Masha and Anderacha. Similarly, the genotype 3 chickens reared in Anderacha district had lower values of albumen height than Yeki and Masha chickens. These variations may be due to agro ecological difference and availability of scavengable feed resources in the three districts. The average albumen height of the current study is in line with the finding of [21, 25] for both local and F1-crosses (genotype 2 and 3). The average albumen height of the current finding for F1-crosses (genotype 2 and 3) was lower than the finding of [18, 20], which might be attributed to the genetic background of exotic chickens, used in the crossbreeding program.

The Haugh unit value of local chicken was higher than the values of F1-crossbred (genotype 2 and 3) chickens across the district and breed except genotype 2 in Yeki and local chicken in Masha district. Thus, suggesting that egg from local chicken posses' better albumen mass than the F1-crossbred chickens across the district and breeds. The average values of Haugh unit for local chicken were in close agreement with those of [27]. On the other hand, the average value of the current finding is lower than the findings of [21, 24, 28, 29]. However, the current findings were higher than those reported by [30] for local chickens raised in north western part of Ethiopia. These variations might be attributed to 
various factors such management differences, age of the birds, quality and quantity of feed and production environments in which the Animals were maintained [21].

The current result showed that the local chicken reared in Yeki district had higher yolk width than chickens reared in Masha and Anderacha; yolk width for Anderacha local chicken was higher than Masha local chicken. Conversely, local chickens reared in Yeki district had lower yolk height than local chickens reared in Masha and Anderacha; yolk height for Masha local chicken was higher than Anderacha local chicken. These variations may be due to environmental and egg storage conditions. The average yolk height of local and F1-cross (genotype 2 and 3) chickens of the current study were lower than the findings of $[20,27,26]$.

The local, genotype 2 and 3 chickens reared in Yeki district had lower values of Yolk colour than chickens reared in Masha and Anderacha but, the genotype 2 chickens in Yeki district was similar with Masha genotype 3 chickens. Thus, the variation might be attributed the availability of scavengable green material in the districts. The average yolk color of local chickens of the current finding is in line with the finding of $[18,20]$. However, the average yolk color of the current finding is higher than the finding of $[1,27,29]$ and was lower than the finding of $[5,26]$.

Such variations in yolk color might be associated with the availability of green feed materials in the scavenging feed resources of various localities.

\section{Conclusions}

The current study indicated that the F1-crosses had higher external egg quality values than those of the local chickens. However, local chickens produced eggs with the highest shell thickness than those of the F1-crosses. Moreover, there were no significant differences observed between local and F1-crossbred chickens in almost all internal egg quality traits and thus might be recommended for egg production purposes in the study areas. However, unplanned distribution of exotic chicken breeds to the study areas will dilute the genetic makeup of the local genetic resources. Authors recommend conducting a comparative on-farm performance study on the egg production and hatchability of the eggs of pure Sasso chicken breed and their F1-crosses under smallholder production systems.

\section{Acknowledgements}

The first author acknowledge the Ministry of Agriculture and Mizan ATVET College for sponsoring the research fund for this post graduate studies and. The collaboration of the College of Agriculture and Veterinary Medicine at Jimma University to use their laboratory to undertake the egg quality evaluation is highly acknowledged. Last but not least, the authors would like to express their gratitude to all households who were willing to collaborate with the researchers while collecting data in the field.

\section{Conflict of interest}

The authors declare that they have no conflict of interests.

\section{References}

[1] Azage, T., Berhanu, G., and Hoekstra, D. (2010). Livestock Input Supply And Service Provision in Ethiopia: Challenges and Opportunities for Market Oriented Development. IPMS (Improving Productivity and Market Success) of Ethiopian Farmers Project Working Paper 20. ILRI (International Livestock Research Institute), Nairobi, Kenya. P. 48.

[2] Alemu, Y. (1995). Poultry production in Ethiopia. World’s Poultry Science Journal, 51: 197-201.

[3] Tadelle, D., Million, T., Alemuy, Peter K. (2003). Village Chicken Production System in Ethiopia. Use Patterns and Performance Evaluation and Chicken Products and Socio-Economic Function of Chicken. Humboldt University of Berlin, Animal Breeding for Tropics and Sub Tropics, Berlin, Germany.

[4] Aberra, M. (2014). Significance of Scavenging Chicken Production in the Rural Community of Africa for Enhanced Food Security, Small-scale Family Poultry Production. World's Poultry Science Journal, Vol. 70.

[5] Fisseha, M., Azage, T., and Tadelle, D. (2010). Indigenous Chicken Production and Marketing Systems in Ethiopia: Characteristics and Opportunities for Market-Oriented Development. Working Paper No. 24; Improving Productivity and Market Success (IPMS) of Ethiopian Farmers Project, International Livestock Research Institute (ILRI). Addis Ababa, Ethiopia, p. 6.

[6] Besbes, B. (2009). Genotype Evaluation and Breeding of Poultry for Performance under Suboptimal Village Conditions. World's Poult. J. Sci., 65: 260-269.

[7] Embet Moreda, S. Hareppal, A. Johansson, T. Sisaye, and Z. Sahile. (2013). Characteristics of Indigenous Chicken Production System in South West and South Part of Ethiopia. British Journal of Poultry Sciences, 2(3): 25-32.

[8] FAO. (2010). Smallholder Poultry Production—Livelihoods, Food Security and Socio-Cultural Significance, By K. N. Kryger, K. A. Thomsen, M. A. Whyte and M. Dissing. Fao Smallholder Poultry Production Paper No. 4. Rome. 
[9] Gueye, E. F. (2003). Poverty Alleviation, Food Security and the Well-Being of the Human Population through Family Poultry in Low Income Food-Deficit Countries. Senegalese Institute of Agricultural Research (ISRA), B.P.2057, Dakar-Hann, Senegal.

[10] Fotsa, J. C., Bordas, A., Rognon, X., Tixier-Boichard, M., Pone Kamdem, D., Manjeli, Y. (2007). Caractérisation Des Élevageset Des Poules Locales et Comparaisonen Station De Leurs Performances À Cellesd'unesouche Commerciale De Type Label Au Cameroun. Journée De La Rechercheavicole, 7, 414-417.

[11] Kingori, A. M., Wachira, A. M., Tuitoek, J. K. (2010). Indigenous Chicken Production in Kenya: A Review. International Journal of Poultry Science, 9(4), 309-316.

[12] Roberts, J. (2004). Factors Affecting Egg Internal Quality and Egg Shell Quality in Laying Hens. Journal of Poultry Science, 41: 161-177.

[13] Solomon, D. (2003). Growth Performance and Survival of Local and White Leghorn Chickens Under Scavenging and Intensive Systems of Management in Ethiopia. Livestock Research for Rural Development, (15)11. www.Irrd.Org/Irrd15/11/Deme1511.Htm.

[14] Serkalem, A., Aberra, M., and Sandip, B. (2018). Egg Production and Linear Body Measurement Traits of Local and Three Exotic Chicken Genotypes Reared Under Two Agroecological Zones. International Journal of Ecology and Ecosolution, 5(2), pp. 18-23.

[15] CSA. (2007). Statistical Report on Population and Housing Census. Volume I, Addis Ababa.

[16] CSA. (2014). Statistical Report on Livestock and Livestock Characteristics (Private Peasant Holdings). Statistical Bulletin 570, Volume Ii, April 2013. Addis Ababa.

[17] Haugh, R. (1937). The Haugh Unit for Measuring Egg Quality. US Egg Poultry. Mag., 43: 522-555, 572-573. http://www.academicjournals.org/AJB, DOI:10.5897/AJB11.1747.

[18] Getachew, B., Bikila, N., Mengistu, U., Negassi, A. (2016). The Study of Egg Quality on Chicken Village in Chelliya District Western Shoa, Ethiopia. ISSN-2350-0530(O) ISSN-2394-3629(P).

[19] Tiambo, C. K., Sylvere, M., Blaise, A. H. T., Celestine, B., Toussaint, M. M., Annie, M. Y. T., Yacouba, M. (2015). Growth Performances, Carcass and Egg Characteristics of the Local Chicken and Its First-Generation Reciprocal Crossbreds with an Exotic Strain in Cameroon. Adv. Anim. Vet. Sci., 3(10): 507-513.

[20] Markos, S., B. Belay, and T. Astatkie. (2017). Evaluation of Egg Quality Traits of Three Indigenous Chicken Ecotypes Kept Under Farmers’ Management Conditions. Int. J. Sci., 16: 180-188.

[21] Aberra, M., Zemene, W., and Yosef, T. (2013). Assessment of the prevailing handling and quality of eggs from scavenging indigenous chickens reared in different agro-ecological zones of Ethiopia. DOC: 10.5455/jeos.20130104091334, http://www.jenvos.com.

[22] C. E. Isidahomen, A. A. Njidda, and E. A. Olatunji. (2013). Egg Quality Traits of Indigenous and Exotic Chickens as Influenced by Specific Genes. Journal of Biology, Agriculture and Healthcare, ISSN 2224-3208 (Paper).

[23] Feyera, B. (2016). Phenotypic Characterization of Indigenous Chicken and their Production System in Gobu Sayo, Bako Tibe and Danno Districts of Western Oromia, Ethiopia. A Thesis Submitted to The School of Animal and Range Sciences, Post Graduate Program Directorate, Haramaya University. P. 81.

[24] Khan, M. K. I., M. J. Khatun, and A. K. M. G. Kibria. (2004). Study the Quality of Eggs of Different Genotypes of Chickens Under Semi-Scavenging System at Babgladesh. Pakistan Journal of Biological Science, 7(12): 2163-2166. ISSN $1028-8880$.

[25] AberraMelesse S. Maak and G. von Lengerken. (2010). Effect of long-term heat stress on egg quality traits of Ethiopian naked neck chickens and their F1 crosses with Lohmann White and New Hampshire chicken breeds. Livestock Research for Rural Development, 22, Article \#71.

[26] Ahamedin, A. and Mangistu, U. (2016). Evaluation of Fertility, Hatchability and Egg Quality of Rural Chicken in Gorogutu District, Eastern Hararghe, Ethiopia. Asian Journal of Poultry Science, ISSN 1819-3609.

[27] Emília Hanusová, Cyril Hrnčár, Anton Hanus, Marta Oravcová. (2015). Effect of Breed on Some Parameters of Egg Quality in Laying Hens. Slovak University of Agriculture in Nitra. Faculty of Agrobiology and Food Resources, http://www.fapz.uniag.sk/.

[28] Desalew, T., Wondmeneh, E., Mekonnen, G., and Tadelle, D. (2015). Comparative study on some egg quality traits of Exotic chickens in different production systems in East Shewa, Ethiopia. African Journal of Agricultural Research, 10(9): 1016-1021. DOI: 10.587/AJAR2014.9373.

[29] Ahmedin, A. (2014). Study of Production Practices, Fertility, Hatchability and Egg Quality of Rural Chicken in Gorogutu District, Eastern Hararghe, Ethiopia. Msc. Thesis Haramaya University.

[30] Halima, H. (2007). Phenotypic and Genetic Characterization of Indigenous Chicken Populations in North-West Ethiopia. Ph.D Thesis. Submitted to the Faculty of Natural and Agricultural Sciences Department of Animal, Wildlife and Grassland Sciences. University of the Free State, Bloemfontein, South Africa. 


\section{Supplementary materials: Sample picture of external and internal egg quality traits.}

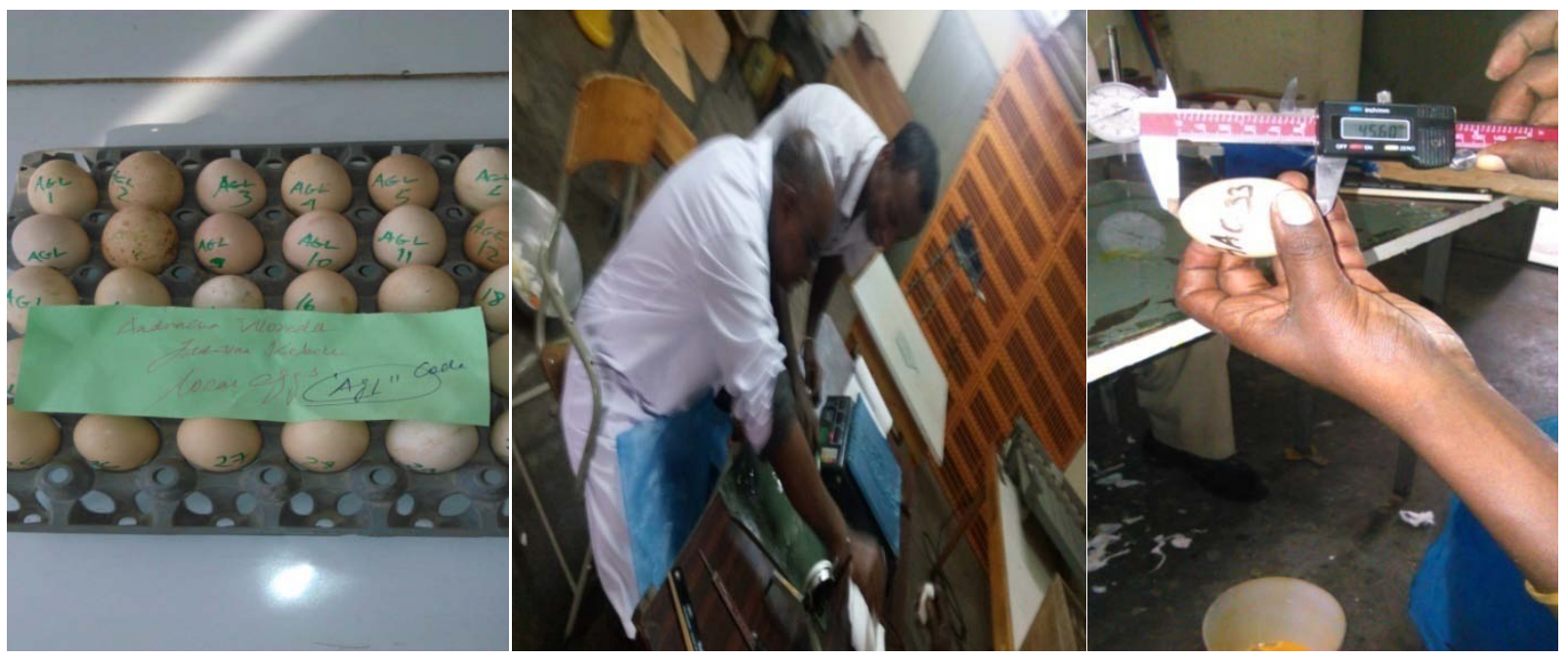

1. Labelling of eggs, working with my major advisor and measuring of egg length from left to right.
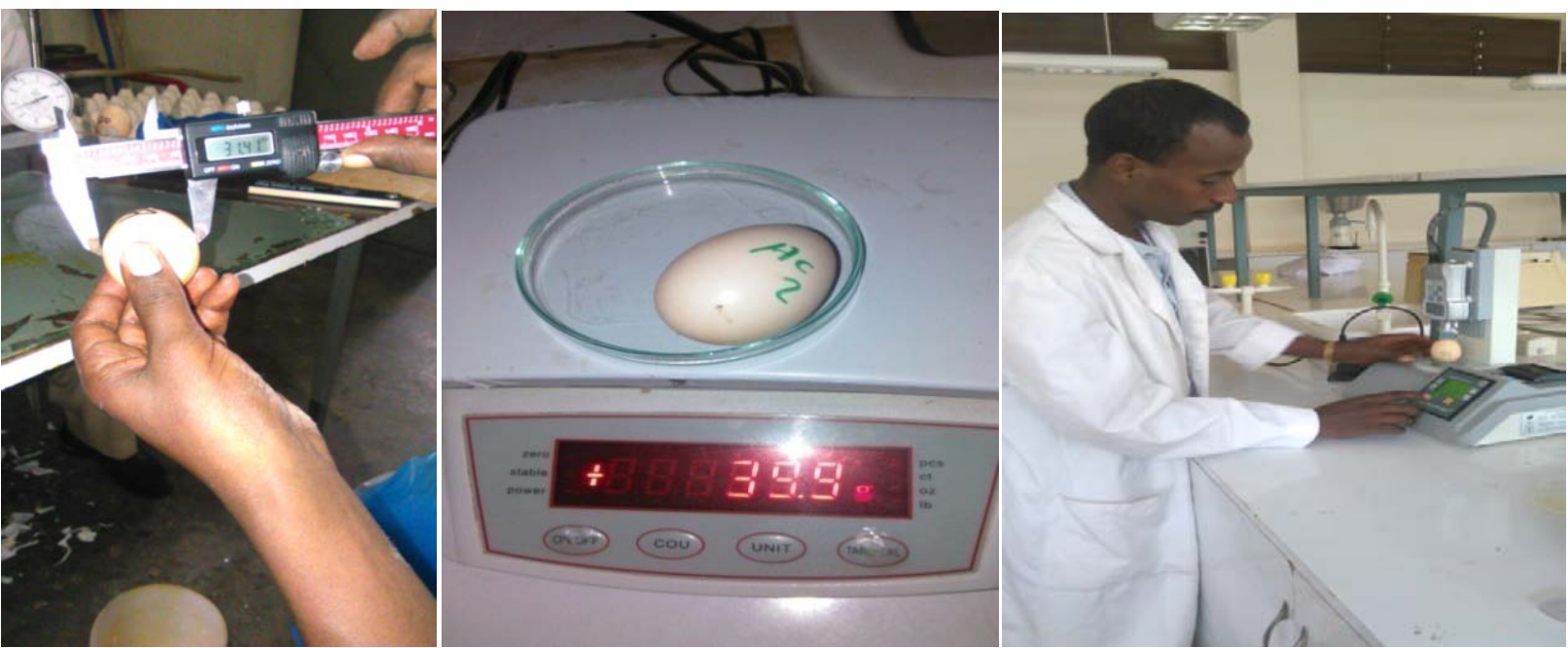

2. Measuring of egg width, weight and shell breaking strength from left to right.

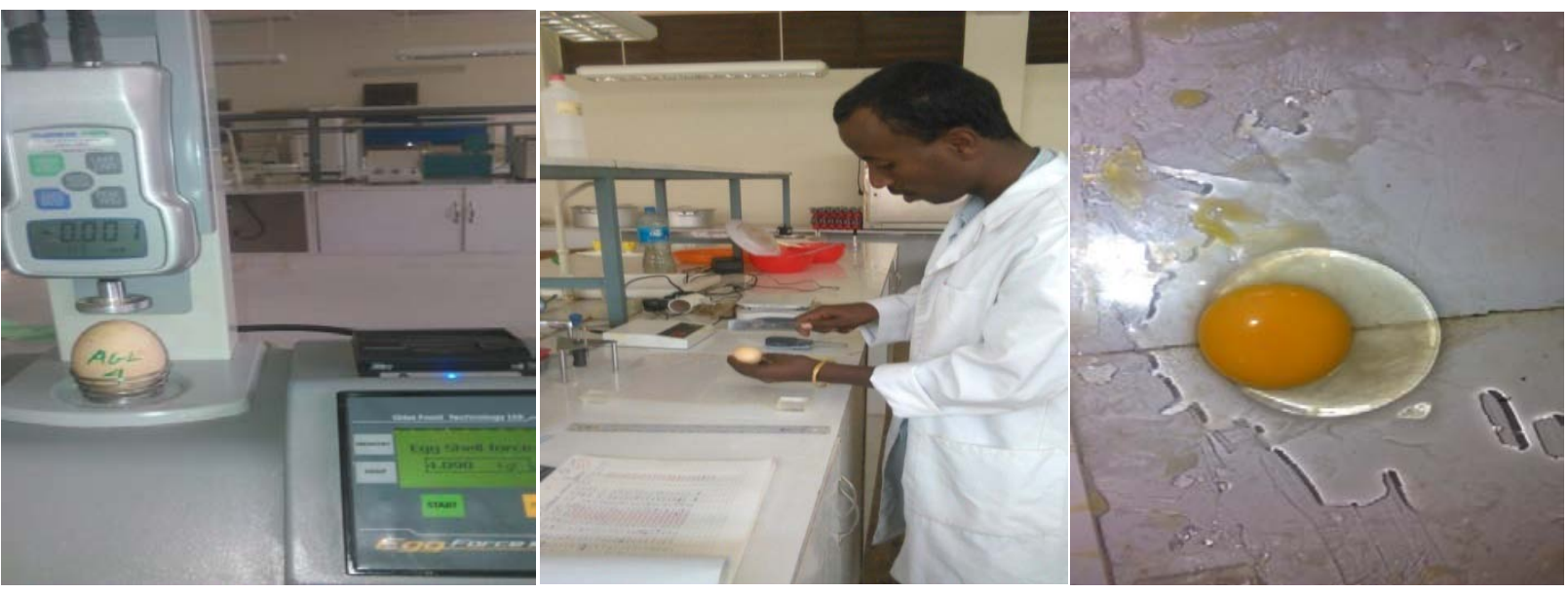

3. Displaying of egg shell breaking strength, breaking of eggs to release albumen and yolk on glass plate. 

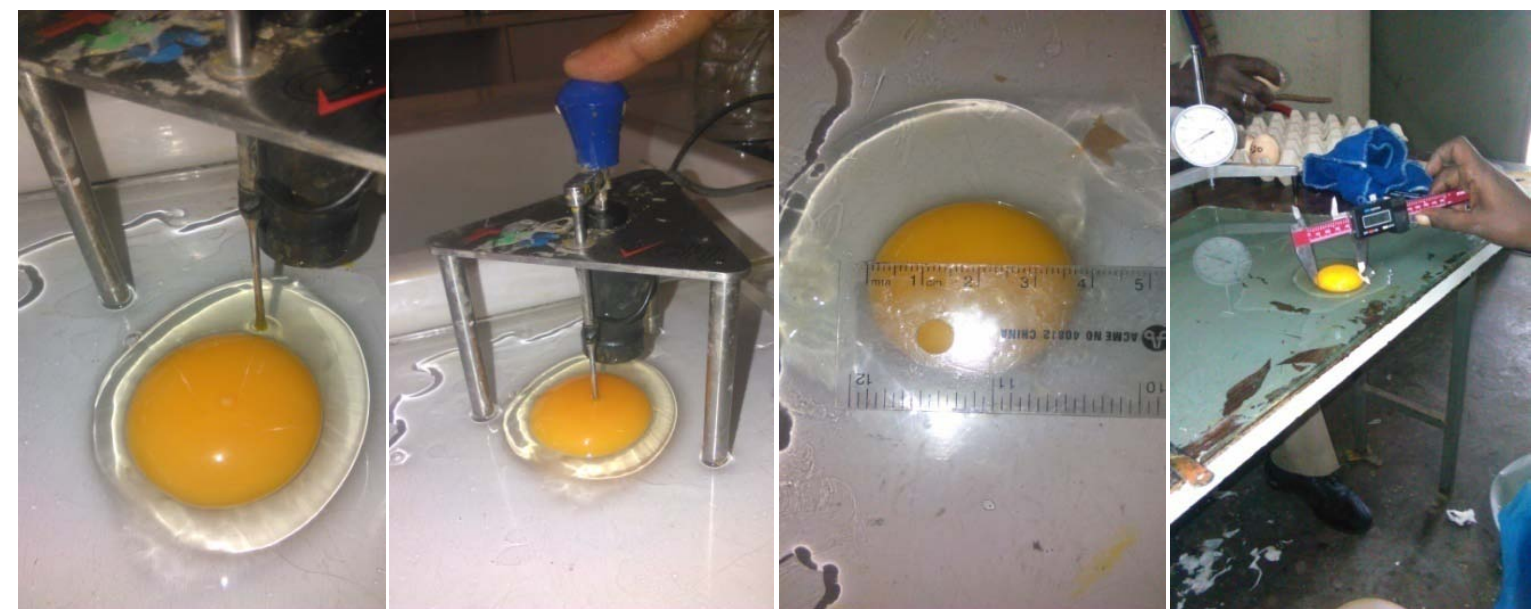

4. Albumen height, yolk height, yolk diameter by ruler and digital calipper from left to right.
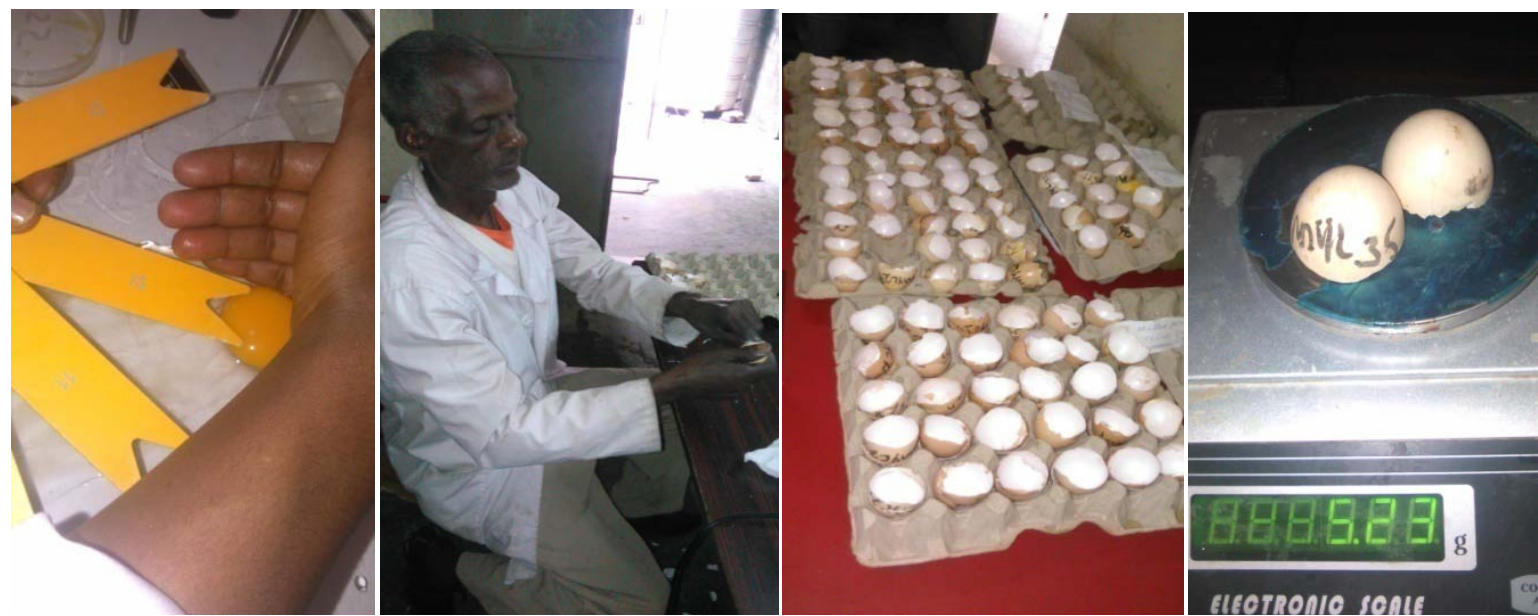

5. Measuring of Yolk color, removing of vitelline membrane, dryad egg shell and weighing of egg shell.

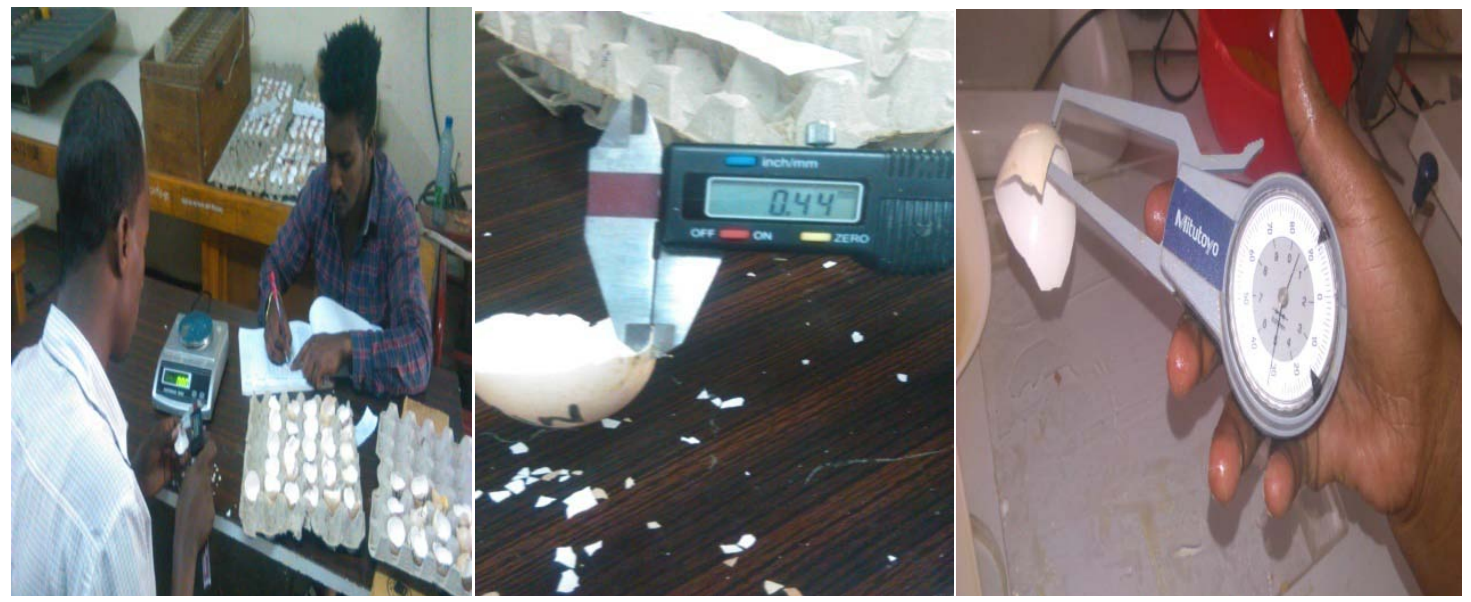

6. Measuring and recording of shell thickens values. 